\title{
O CONCEITO DE PAISAGEM E SUA APROPRIAÇÃO PELO TURISMO: O EXEMPLO DAS IMAGENS NAS BAIXADAS LITORÂNEAS (RJ)
}

\section{The concept of landscape and its appropriation by tourism: the example of the images in the Baixadas Litorâneas (RJ)}

\author{
Nathan da Silva Nunes \\ Mestrando pelo programa de Pós-Graduação em Geografia (PPGEO-UERJ) \\ nunesuerj@gmail.com
}

Artigo recebido em 22/01/2017 e aceito para publicação em 11/07/2017

DOI: $10.12957 /$ tamoios.2017.26993

\section{RESUMO}

O presente artigo desenvolve uma abordagem acerca do conceito de paisagem desde sua concepção e posterior apreensão pelos estudos geográficos, para que a mesma seja analisada enquanto ferramenta utilizada pelo Turismo. No contexto apresentado, a análise da maneira como atuam os agentes ligados a esta atividade socioeconômica complexa, valendo-se da criação e propagação de imagens idealizadas dos lugares, e suas implicações, é fundamental para a compreensão de seu desenvolvimento atualmente. $\mathrm{O}$ recorte selecionado abrange os municípios das Baixadas Litorâneas, no estado do Rio de Janeiro, região de destaque no que tange ao desenvolvimento do setor a partir da década de 1970, tendo como fatores de influência a construção da Ponte RioNiterói, a ampliação da BR-101 e a propagação de representações de suas paisagens através de cartões postais e posteriormente da internet.

Palavras-chave: Paisagem; turismo; imagem; Rio de Janeiro; Baixadas Litorâneas.

\section{ABSTRACT}

This article develops an approach about the landscape concept since its inception and subsequent arrest by geographical studies, for it to be analyzed as a tool used by Tourism. In the context presented, the analysis of how work the agents connected to this complex socioeconomic activity, drawing upon the creation and spread of idealized images of the places, and its implications, it is essential for understanding its current development. The selected snippet covers the municipalities of Baixadas Litorâneas, in the state of Rio de Janeiro, a region of outstanding importance for the development of the sector since the 1970s, having as influence factors the construction of the RioNiterói Bridge, BR-101 and the spread of representations of its landscapes through postcards and later the internet.

Key-words: landscape; tourism; image; Rio de Janeiro; Baixadas Litorâneas. 


\section{INTRODUÇÃO}

O conceito de paisagem, tão caro à Geografia, sofreu ao longo de sua história importantes modificações conceituais, a partir de inúmeros pesquisadores e correntes de pensamento da qual faziam parte, sendo entendido muitas vezes como polissêmico, tal conceito foi deixado em segundo plano durante diversos períodos, ressurgindo a partir da década de 1970 e retomando sua importância para a ciência geográfica.

Procuraremos inserir a discussão acerca da paisagem em temáticas inerentes ao turismo, setor tão destacado na economia do estado do Rio de Janeiro, notadamente nos municípios constituintes da mesorregião das Baixadas Litorâneas, importantes receptores de fluxos populacionais desde a década de 1970.

Dessa forma, torna-se importante a utilização desta vasta bibliografia para realizar a discussão, tendo como objetivos: apresentar o conceito de paisagem e sua utilização pela Geografia; investigar o processo de transformação de paisagens em mercadoria a partir do fenômeno da globalização; analisar como a atividade turística se vale das imagens para sua difusão, tendo como recorte espacial a região das Baixadas Litorâneas-RJ.

A metodologia utilizada neste artigo compreendeu o levantamento bibliográfico referente às variadas concepções conceituais da paisagem, bem como a respeito de sua apropriação pelo capitalismo e, mais especificamente, pelo turismo, com a intensificada propagação de imagens das paisagens selecionadas e valorizadas pelos agentes que atuam neste setor. Foram utilizados também cartões postais cedidos pela colecionadora Elaine Damasio, afim de ilustrar a discussão que trata de sua utilização como ferramenta de propagação de destinos turísticos no estado do Rio de Janeiro; e material publicitário adquirido através de trabalho de campo no município de Armação dos Búzios, bem como as contribuições oriundas da observação realizada quando desta atividade.

\section{O CONCEITO DE PAISAGEM: DA ARTE À GEOGRAFIA}

Ao tratar do surgimento do conceito de paisagem, é impossível deixar de mencionar a decisiva contribuição realizada pela arte, em especial quando tratamos da pintura. Segundo Salgueiro (2001), esta desempenhou fundamental papel para a transformação da maneira como a natureza era vista pela sociedade (até então como algo sagrado) ao auxiliar na construção dos códigos estéticos de apreciação da mesma. A paisagem acaba por transgredir a antiga concepção religiosa do pecado, mas não apenas isso, também a criação divina da natureza. Dessa forma, o homem passa a ter maior autonomia e controle sobre as coisas do mundo concomitantemente com o desenvolvimento de diversos campos da ciência que influenciam diretamente nas expedições marítimas e a descoberta de novos territórios (KERN, 2011).

Colaborou com essa nova forma de perceber e lidar com a natureza a transformação no modo de vida das sociedades, passando agora a um momento de 
aceleração do processo de urbanização que por consequência gerou contato menor e menos profundo com o meio natural, como explicita Kern $(2011$, p.2)

\begin{abstract}
Recuperá-lo significa construir uma relação que tem por base a perda e reinventá-lo no plano simbólico e estético, para poder ter o prazer de desfrutá-lo visualmente. A paisagem coloca a nu a complexidade do mundo moderno e de um novo gênero de representação, que tem como fim apresentar o homem e o seu olhar sobre a natureza.
\end{abstract}

Para a Geografia, o século XIX foi determinante para a paisagem enquanto foco de análise, tendo como ponto de partida o momento em que torna-se disciplina científica na Alemanha, sendo possível identificar duas maneiras mais utilizadas ao estudar a paisagem. Salgueiro (2001) explica que para alguns pesquisadores o estudo baseava-se no método morfológico, privilegiando as formas, enquanto para outros geógrafos as características físico-naturais e humanas e suas inter-relações eram priorizadas.

Em espacial a partir do último quarto do século XX, após considerável período em que a ciência geográfica preocupou-se de maneira mais destacada com estudos voltados a outros conceitos, a paisagem volta a cena e as relações entre indivíduos e o ambiente passam a ser novamente motivo de atenção por parte de geógrafos (SALGUEIRO, 2001). Este novo momento de estudos da paisagem se explica pela necessidade de análise da crescente exploração de recursos pela sociedade capitalista, não estimulando que haja retorno à ideia de natureza santificada, mas tendo como objetivo traçar perspectivas racionais a respeito das ameaças inerentes a tal prática.

Visando trazer maior aporte teórico este segmento, é importante apresentar algumas definições de paisagem segundo publicações recentes, como Salgueiro (2001, p.43-44), que apresenta o conceito como durante muito tempo foi aceito pelos geógrafos, para em seguida trazer as definições mais recentes

Durante muito tempo os geógrafos aceitaram que a paisagem era a porção do espaço geográfico que se abrangia com o olhar, estudando como paisagem as características deste espaço. Se pensarmos nas definições de paisagem que aparecem na literatura geográfica dos últimos anos verifica-se uma transição de enfoque do objectivável (físico/ecológico) para o fenomenal (o modo de ver, a relação sujeito/objeto).

Verri (2008, p.13), apresenta as percepções do geógrafo Milton Santos, explicando o que este pensa sobre a paisagem

A distância entre o observador e o seu objeto resultam variadas paisagens, panoramas vistos de um avião, de um mirante, de um edifício, de uma rua, de uma árvore, de uma montanha. Para Santos a dimensão da paisagem depende do que os sentidos permitem perceber (como foi destacado através do olhar), a apreensão é seletiva com base em elementos cognitivos formados através de processos formais ou informais de educação. Por esse motivo, a paisagem pode ser apreendida de diversas maneiras por diferentes pessoas.

Analisando as concepções apresentadas, é evidente que a temática ainda causa divergências quanto ao seu conteúdo, o que indica a necessidade de intensificação de 
estudos a seu respeito por parte de geógrafos. Contudo, para a análise aqui proposta, há um aspecto contido nestas definições que apresenta-se como norteador, que diz respeito ao caráter subjetivo da apreciação da paisagem. Essa interpretação tende a valorizar a construção mental oriunda da percepção dos indivíduos, além da vivência no território.

O que há de constatação, portanto, é o número crescente de geógrafos que passam a priorizar o enfoque fenomenal quando das pesquisas ligadas à paisagem, esta sendo entendida como cada vez mais subjetiva, valorizando as representações desenvolvidas por cada indivíduo a respeito do mundo. Para o desenvolvimento da temática aqui proposta, é fundamental a abordagem de

Salgueiro (2001, p.47) quando trata das correntes atuais, explica ainda que pela ótica marxista podemos ver "a paisagem artefacto vinculada a uma ideologia dominante, ao modo como se organiza a exploração dos recursos naturais". Parece claro que para o estudo sobre o desenvolvimento do setor turístico enquanto atividade econômica, a subjetividade e a apropriação capitalista da paisagem são de extrema importância, sendo privilegiadas nos segmentos seguintes deste trabalho, quando serão discutidas a globalização e a importância do discurso vendido a partir de cartões postais.

\section{A INFLUÊNCIA DA GLOBALIZAÇÃO PARA A CRESCENTE MERCANTILIZAÇÃO DE PAISAGENS}

Com a acentuação do processo de globalização, a atuação de determinados atores torna-se mais evidente, interessando aqui as práticas daqueles que interferem sobre as paisagens, como os responsáveis por políticas públicas, a mídia e agências de turismo. Salgueiro (2001) aborda a temática e chama a atenção para a "intensificação da exploração econômica da paisagem no mundo capitalista", observada especialmente na ação de agentes ligados ao turismo. Corroborando com esta autora, Verri (2008, p.16) destaca que

signos característicos como certas espécies animais e vegetais em extinção materializam-se na televisão, cinema, revistas, folders das agências de ecoturismo, etc. Este objeto, presente em paisagens naturais espetaculares, ganha imediatamente um valor.

Para tratar do fenômeno turístico precisando compreender minimamente sua origem e as práticas que o transformaram no que podemos observar hoje. Desta forma, podemos caracterizá-lo como uma atividade originada nas evoluções tecnológicas no século XIX, associada à criação da primeira agência de viagens, na Inglaterra, tendo como público alvo a burguesia britânica. A inclusão da classe trabalhadora enquanto consumidora da oferta turística tem início após a Segunda Guerra Mundial, pois países industrializados começaram a adotar medidas como a redução da jornada de trabalho, que acarretou em maior tempo livre.

Tais ações contribuíram decisivamente para a afirmação do turismo como atividade econômica geradora de recursos nas décadas seguintes (CORREA, 2010). Porém, a ampliação de oferta e demanda não gerariam o esperado resultado sem que houvesse uma revolução tecnológica, abordada por Fiori (2007), modificando a 
extensão, a velocidade e o custo da circulação de informações, produtos e pessoas. Os processos citados influenciam para que aconteça em larga escala "a privatização do tempo livre ocorre na medida em que conquistas trabalhistas são alcançadas, as necessidades do ócio são salientadas e na possível rentabilidade de atividades vinculadas ao lazer" (MARTONI, 2006, p.6).

Assim podemos compreender as razões para que a prática turística tenha apresentado crescimento destacado nas últimas décadas, muito em função da expansão no número de destinos oferecidos, alterando a tradicional tendência de concentração nos países desenvolvidos enquanto principais beneficiados com fluxos populacionais e receitas. É nesse contexto que emergem os atores anteriormente citados, visto que a abertura de novos mercados a este setor ocorre em grande parte devido à atuação dos governos de países periféricos em associação com grandes grupos capitalistas ligados ao transporte, hotelaria e gastronomia, por exemplo.

A visão de Neto (2010) sobre tal cenário apresenta uma perspectiva otimista quanto aos resultados desse processo, visto que o autor entende que a paisagem "desempenha importantes funções de interesse público (...) e constitui um recurso favorável à atividade econômica, cuja tutela e gestão adequadas podem contribuir para a criação de emprego e renda dos cidadãos". Entretanto, a supracitada gestão adequada tende a ser exceção, já que a regra, como mostra Abreu (2007, p.75), costuma ser "o domínio da visão de curto prazo, não só por parte da população em geral mas, sobretudo, por parte dos decisores com maior responsabilidade neste âmbito", este prossegue afirmando que há

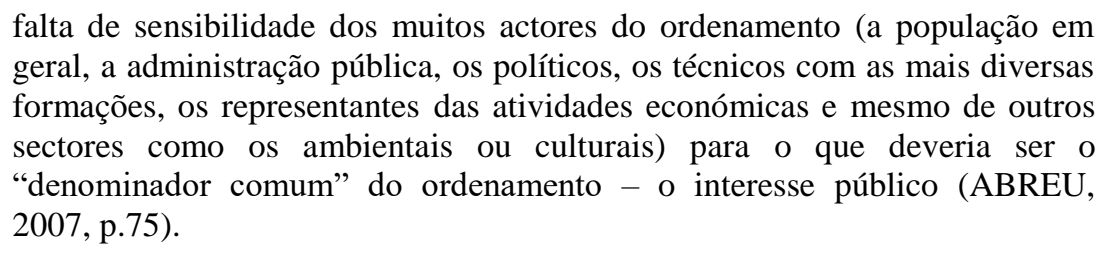

A visão imediatista por parte do poder público ocasiona uma abertura demasiada aos agentes do setor privado, que devido aos preceitos de sua atividade, usufruem de facilidades como subsídios, mão de obra farta e barata, e o principal, livre atuação quanto às paisagens, tornando-as meras mercadorias.

Há outro perigo na constituição destes discursos que diz respeito à fabricação de culturas, com os agentes responsáveis trabalhando na seleção e/ou invenção de determinados símbolos padronizados a serem vendidos, tendo como resultado desse processo a exclusão de elementos constituintes da cultura local. Antunes (2008) atenta para este fato, entendendo que "corremos o sério risco da globalização da paisagem permitir uma tal homogeneidade que se perca a identidade do lugar e o respectivo estatuto".

Este cenário está associado diretamente à ausência de legislação específica sobre o direito a paisagem em países como o Brasil, que por isso necessita usar como referência a Convenção Europeia da Paisagem. Tal carência é prejudicial na medida em que o país 
parece não reconhecer a importância da paisagem para o interesse público ambiental, cultural e socialmente, dificultando que ocorra maior fiscalização e melhor gestão quanto aos impactos promovidos pelo turismo, acarretando que os resultados obtidos sejam insatisfatórios à grande parte de sua população, que teoricamente deveria ser a maior ganhadora neste processo.

\section{TURISMO NAS BAIXADAS LITORÂNEAS: TENTATIVA DE CONVENCIMENTO A PARTIR DE IMAGENS DA PAISAGEM}

Este último segmento tratará do turismo no estado do Rio de Janeiro, apresentando características das paisagens que fazem este estado ter destaque no cenário nacional e a forma com que estas são exploradas para a criação de uma imagem vendida externamente, mais especificamente a mesorregião de governo das Baixadas Litorâneas.

Inicialmente, é válido caracterizar o Turismo, atividade que teve origem a partir das evoluções tecnológicas no século XIX, associada à criação da primeira agência de viagens, na Inglaterra, tendo como público alvo a burguesia britânica. Após a Segunda Guerra Mundial ocorre a inclusão da classe trabalhadora como consumidora da oferta turística, devido à adoção de medidas que propiciavam maior tempo livre nos países industrializados. Por seu caráter multifacetado a suas implicações culturais, sociais e econômicas, o turismo tornou-se tema de grande interesse à Geografia nas últimas décadas.

Ao tratar da apropriação de paisagens pelo turismo e sua investigação geográfica, deve-se frisar que mesmo que a geografia humana privilegie recentemente as questões subjetivas e sensíveis quando da análise destas, é importante em diversas pesquisas que haja a caracterização dos aspectos físicos da área em análise, como fazem Egler e Pires do Rio (2004, p.8) ao tratarem do estado do Rio de Janeiro

\footnotetext{
O conjunto de serras que formam a borda do Planalto Atlântico, aliado ao extenso litoral, ora profundamente recortado na Costa Verde, ora com vastas extensões de lagoas e restingas na Região dos Lagos, resulta em um mosaico diferenciado de paisagens. (...) Tais paisagens foram funcionalizadas desde o período colonial, onde as grandes reentrâncias costeiras formadas pela Baía da Ilha Grande, de Sepetiba e da Guanabara constituíam abrigos naturais para a navegação, ao mesmo tempo em que os primórdios rochosos, como o de Arraial do Cabo e de Armação dos Búzios, avançam mar adentro, facilitando a pesca e captura de baleias, cujo óleo foi essencial para a construção urbana nos primórdios da colonização.
}

Quando olhamos externamente à ciência geográfica, é possível observar historicamente destaque ainda maior às belezas naturais encontradas em Armação dos Búzios, Cabo Frio, Arraial do Cabo e diversos outros municípios, partindo da grande mídia, prefeituras municipais e agências de turismo. Tais aspectos naturais, juntamente com o marketing a elas relacionado, resulta no que observamos através da classificação desenvolvida pelo Ministério do Turismo (2015) para os 92 municípios que formam o estado do Rio de Janeiro, onde vários desta mesorregião aparecem com destaque (quadro 1). 
Quadro 1- Classificação turística dos municípios das Baixadas Litorâneas

\begin{tabular}{|c|c|c|}
\hline Município & Categoria & Região Turística \\
\hline Araruama & C & Costa do Sol \\
\hline Armação dos Búzios & A & Costa do Sol \\
\hline Arraial do Cabo & B & Costa do Sol \\
\hline Cabo Frio & A & Costa do Sol \\
\hline Casimiro de Abreu & C & Costa do Sol \\
\hline Iguaba Grande & C & Costa do Sol \\
\hline São Pedro da Aldeia & C & Costa do Sol \\
\hline Saquarema & B & Caminhos da Mata \\
\hline Silva Jardim & D & \\
\hline
\end{tabular}

Fonte: Ministério do Turismo, 2015. Elaborado por Nunes (2016).

Neste cenário, a comercialização de cartões postais (figuras 1 e 2) exerceu, juntamente com a construção da Ponte Rio-Niterói e a expansão e asfaltamento de rodovias ligando a capital ao interior, papel importante a partir de década de 1970 para a intensificação dos fluxos turísticos em direção à região das Baixadas Litorâneas. Posteriormente, a partir do início do século XXI, presenciamos um novo período, onde as imagens impressas dão lugar às efêmeras propagadas através da internet, em um primeiro momento pelo email e atualmente pela instantaneidade das chamadas redes sociais. 
Figura 1 - Cartão postal da praia João Fernandes, em Armação dos Búzios
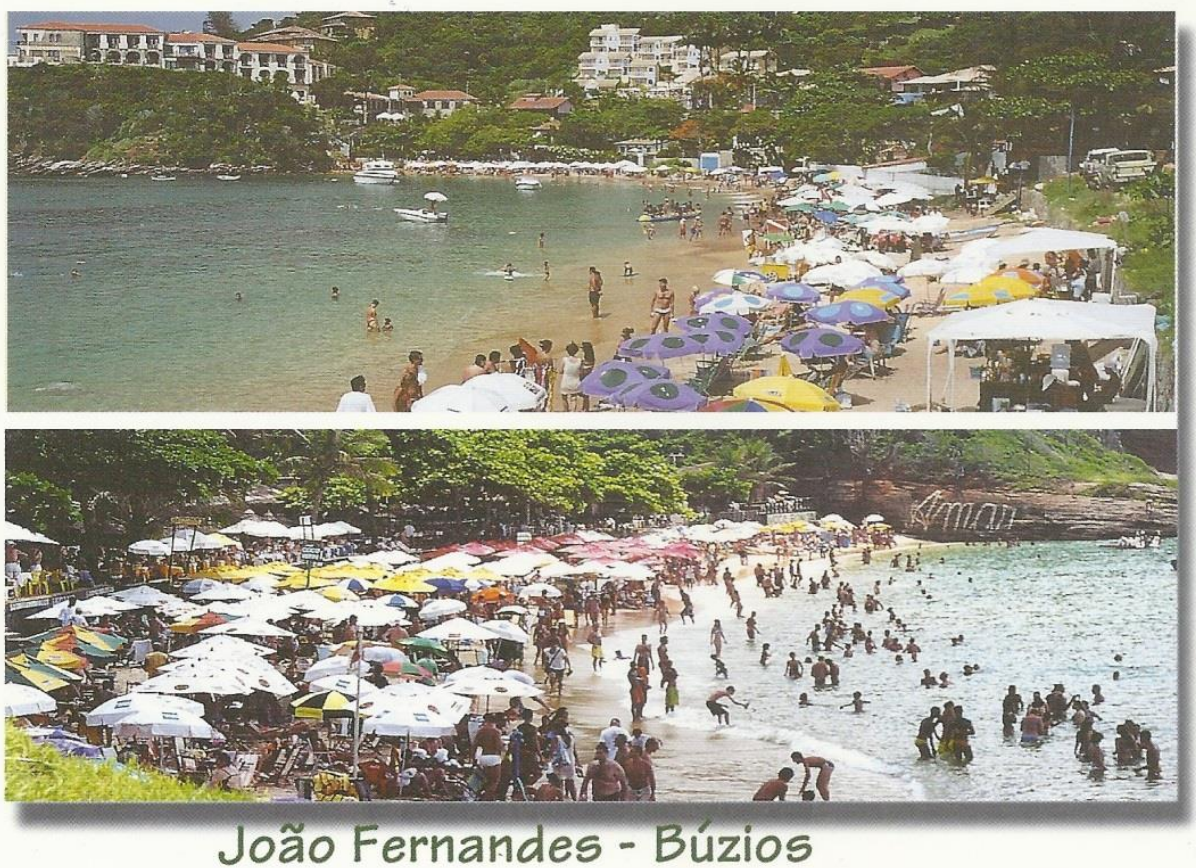

Fonte: Rodolpho Machado, 2003.

Figura 2 - Cartão postal representando uma paisagem do município de Saquarema

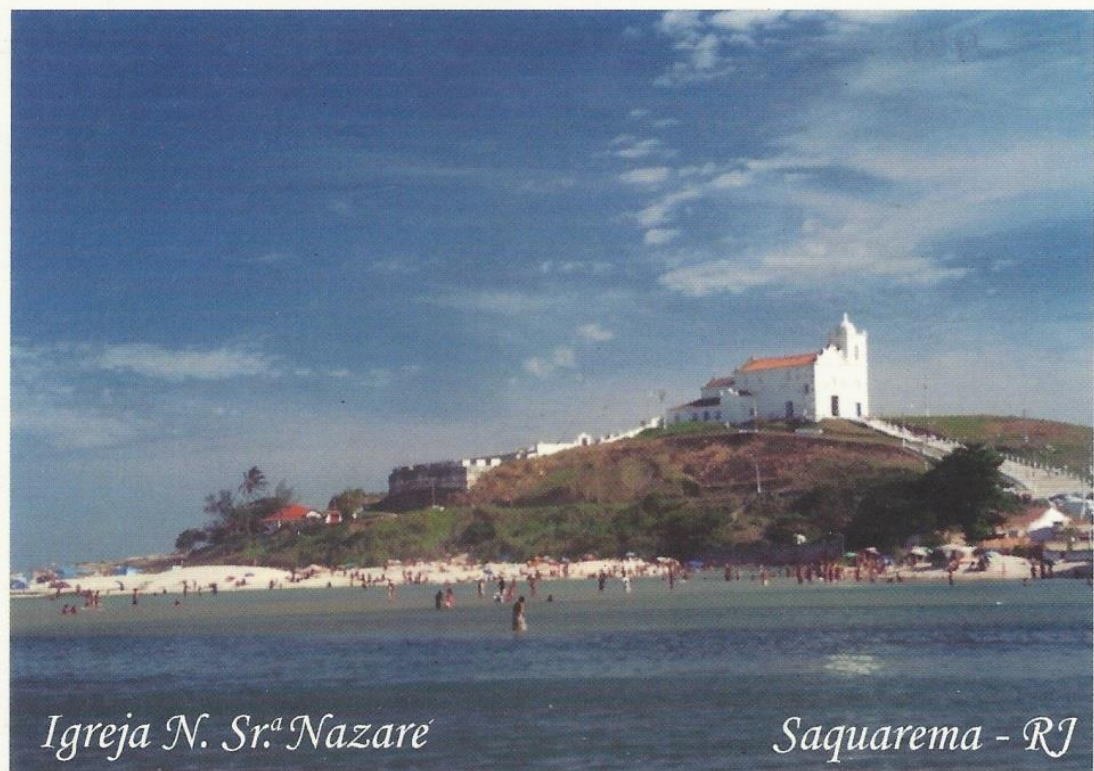

Fonte: Rodolpho Machado, 2003.

Ressaltamos que a propagação de representações da paisagem a partir de imagens contidas em cartões postais insere-se num contexto de desenvolvimento turístico a partir de campanhas do poder público que visam ordenar a configuração espacial, estas são pontos de vista autorizados. Sayão $(2011$, p.12) aponta que 
A fotografia da paisagem é uma pausa pacífica envolta na atmosfera mágica, quase palpável da saudade. Ao mesmo tempo, a paisagem do postal consagra o cenário ideal do futuro, é o território que todo governante gostaria de ter para governar.

Para autores como Fernandes (2008) os cartões postais merecem ser valorizados atualmente por sua importância histórica, devido a seu poder diacrônico, que possibilita uma viagem no tempo ao observador, que "visita" lugares e paisagens do passado. Entende-se, porém, que para representações atualizadas da paisagem

Porém, em função da crescente competitividade entre os lugares, a mera seleção de um recorte espacial e sua propagação em forma de fotografia não tem sido suficiente nos últimos anos, sendo necessário que o discurso vinculado passe a ir além da simples apreciação dos aspectos de ordem física da natureza, agora a busca é pelo convencimento da possibilidade de retorno às origens, a uma paisagem dita natural, em contraposição à agitada e estressante vida nas grandes cidades. A carga subjetiva na análise de uma paisagem passa a ser também vendida ao turista através do discurso construído em cima das imagens, agora o viajante já vai ao destino selecionado carregado de expectativas quanto aos sentimentos provocados pelo local. A seleção do recorte e a mensagem a ser transmitida obedecem alguns critérios, segundo Verri (2008, p.16)

\begin{abstract}
O enquadramento deste objeto obedece a determinados critérios de focagem, como e o que emoldurar, harmonizar em cores, objetos, e luzes. Critérios que parecem aliar -se ou usar idéias próprias como inspiração e determinação resultam em imagens construídas tendo como base a afirmação de valores preestabelecidos.
\end{abstract}

Há nestes discursos minuciosamente construídos uma ideia que remete às discussões de séculos passados quando se trata de paisagem: a diferenciação entre paisagens natural e cultural. Tratando especificamente do recorte espacial que abrange a região das Baixadas Litorâneas, é possível conceber que haja ainda hoje algo que não foi influenciado pelo homem? Verri (2008, p.15) auxilia na discussão trazendo sua concepção de paisagem natural e o uso que o turismo faz deste termo

\footnotetext{
A ideia de paisagem natural poderia ser entendida como ausência de relações sociedade-espaço. Entretanto, a paisagem natural transforma-se em produto da sociedade quando seu espaço ganha valor de uso para o turismo. A 'volta à natureza' baseada em aspirações ligadas ao uso, à reconstituição do prazer, ao ser incorporada como valor de uso para a atividade turística, é imediatamente transformada em valor de troca.
}

O exposto evidencia a preocupação dos agentes capitalistas ligados ao turismo em vender os elementos selecionados do lugar. Como exemplo dentro da mesorregião estudada, tem crescido no município de Casimiro de Abreu a procura por atividades ligadas ao consumo da natureza, especialmente aquelas voltadas à prática de esportes radicais, valorizando assim seu potencial para a prática de esportes, lazer e também seu patrimônio paisagístico e cultural. Através de pesquisa digital no acervo do jornal $O$ Globo é possível encontrar diversas reportagens a respeito do turismo crescente no 
município, com o verde da natureza sendo constantemente destacado nas fotografias que ilustram as matérias jornalísticas (figura 3). Nesse caso, há o perigo de uma aceleração do processo de destruição do patrimônio, pois as agências e, por consequência, seus clientes atuam diretamente na natureza a partir da infraestrutura necessária, visto que não é tarefa fácil evitar o impacto na paisagem que decorre de infraestruturas ou mesmo a construção de residências.

Figura 3 - Imagem fotográfica de Casimiro de Abreu destacando o verde da natureza

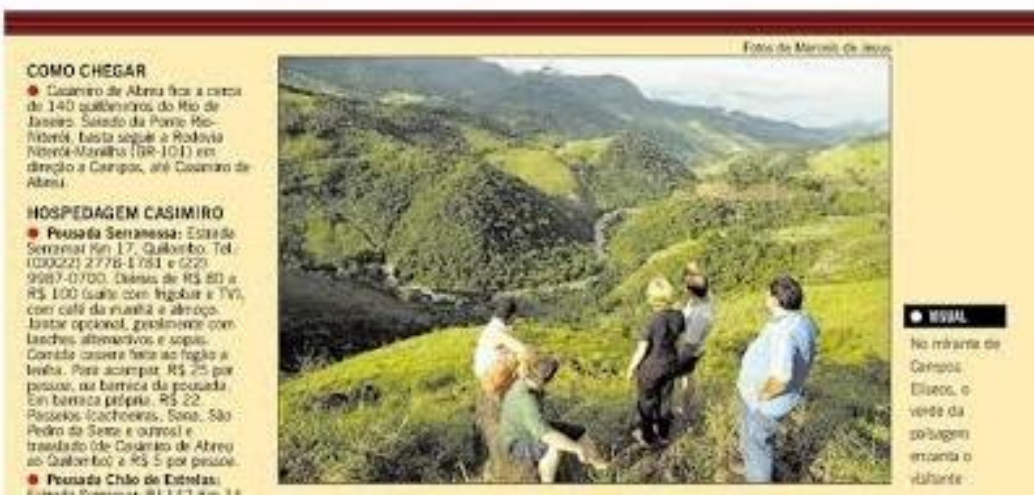

Fonte: Jornal O Globo, março de 2003.

O exemplo de Armação dos Búzios talvez seja ainda mais claro, tendo a fotografia desempenhado ao longo das décadas papel central no processo de transformação da cidade em mercadoria (figura 4). Quanto a isto, Xavier (2006, p.123) chama a atenção

Apreendidas em seleções fotográficas, utilizadas em encartes e folders turísticos, expostas em revistas, jornais e até mesmo nos álbuns particulares de turistas, algumas paisagens tornadas espetaculares passaram, ao longo do anos, a simbolizar Búzios.

Neste cenário, as imagens propagadas serviram e continuam servindo como convite ao retorno ou primeira visita de turistas ávidos pela exuberância retratada. A realidade em miniatura contida nas fotografias apresenta informações possivelmente verdadeiras, mas exclui do olhar turístico o que há em seu entorno. Ao visitar o local, o viajante, cercado de expectativas prévias e já orientado a buscar os cenários que lhe foram vendidos, tem seu comportamento completamente direcionado à reprodução (agora a partir de sua própria máquina fotográfica) daquelas imagens, que costumam ter a dita paisagem natural como principal elemento. 
Figura 4- Material publicitário distribuído pela prefeitura de Armação dos Búzios

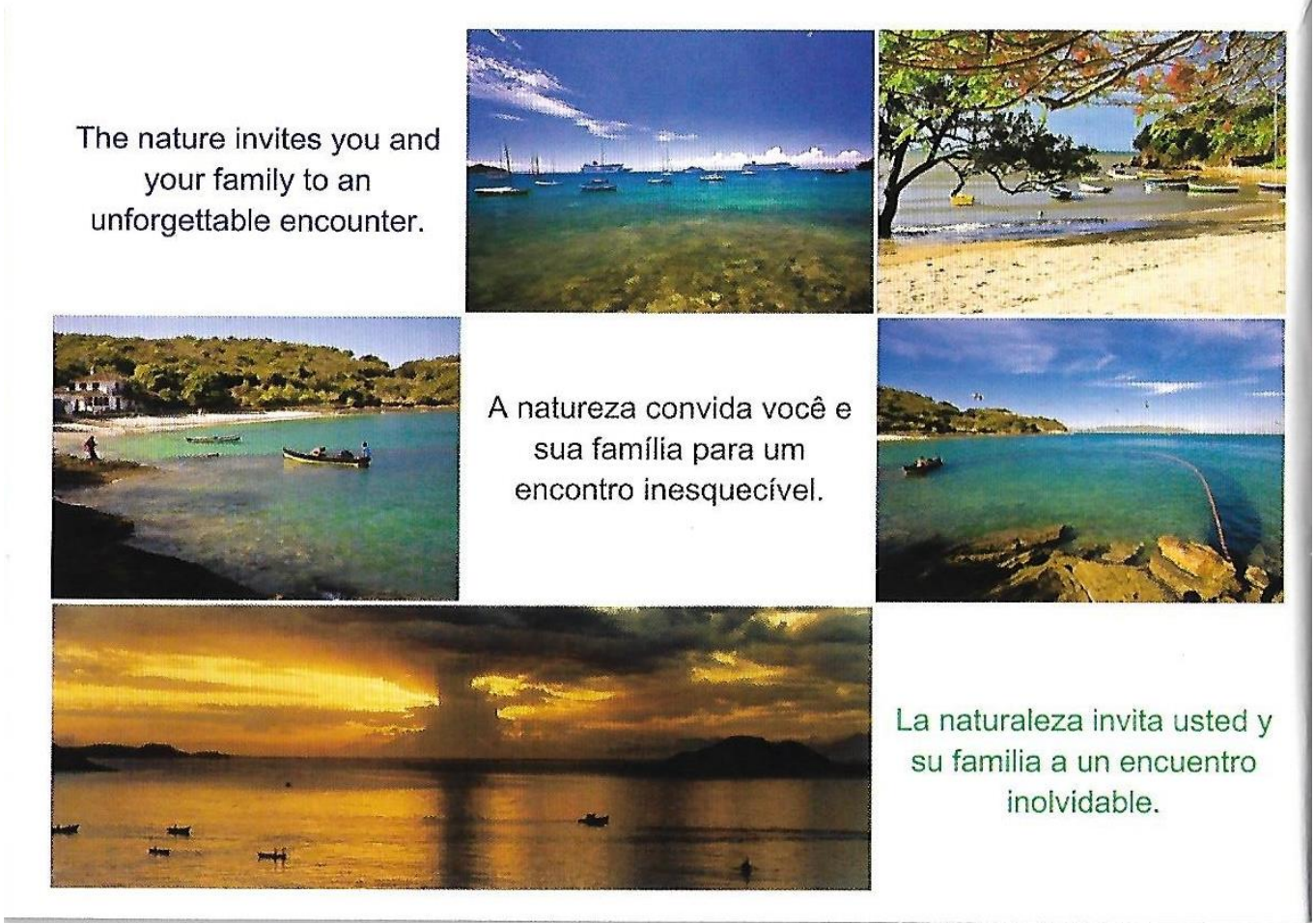

Fonte: Secretaria de Turismo, Cultura e Patrimônio Histórico de Armação dos Búzios, s/d.

Todavia, como já abordado, não há como se falar em paisagem natural segundo uma perspectiva geográfica, pois mesmo que houvesse porções de território até então inexploradas, a inserção da atividade turística já seria suficiente para modificar esse cenário. Com isso, conclui-se que o discurso construído através de imagens selecionadas e os ideais nelas contidos apresenta-se como fantasioso e estritamente comercial.

\section{CONCLUSÃO}

O conceito de paisagem, tão caro à Geografia, sofreu e ainda sofre transformações desde seus primeiros estudos por esta ciência. A valorização dos aspectos subjetivos possibilitou a construção do cenário visto atualmente, onde a recuperação do conceito tem possibilitado grande diálogo sobre a relação entre sociedade e ambiente. No que tange ao turismo, este usufrui (em grande parte de suas categorias) desta relação ao se apropriar e mercantilizar os mais diversos aspectos da natureza, fazendo valer um discurso criado e propagado pelos atores que através dele obtém benefícios.

Por parte da população, é necessário que haja maior senso crítico, fugindo da alienação que frequentemente buscamos quando nos encontramos no papel de turista. A procura por descanso e lazer não deve ser esquecida, porém devemos criar nossa própria representação do mundo, através da objetividade e subjetividade (VITTE, 2010), dessa forma é possível escapar dos discursos pasteurizados, possibilitando que o belo não se restrinja ao campo da visão (BECKERT, 2007), mas que a compreensão faça da experiência de viajar algo positivo e acrescente na maneira como habitamos o mundo. 


\section{REFERÊNCIAS BIBLIOGRÁFICAS}

ABREU, Alexandre d'Orey Cancela. Paisagem e ordenamento do território. In: Inforgeo. Julho, 2007.

ANTUNES, Luís Filipe Colaço. Direito público do ambiente - Diagnose e prognose da tutela processual da paisagem. São Paulo: Editora Almedina, 2008.

BECKERT, Cristina. A experiência estética da natureza. In: Philosophica. Lisboa, 2007. P. 717.

CORREA, Ana. Las ciudades y el turismo em el nuevo escenario internacional. In: Ciudades, turismo y cultura. Buenos Aires: La Crujía, 2010. P. 21-32.

EGLER, Claudio A. G.; PIRES DO RIO, Gisela A. Turismo e desenvolvimento local no Estado do Rio de Janeiro. VIII Encontro Nacional de Turismo com Base Local. Curitiba, 2004.

FIORI, José Luiz. A grande transformação do fim do século XX. In: O poder global. Saõ Paulo: Boitempo Editorial, 2007, pp.49-53.

MARTONI, R. M.. Turismo e Capitalismo: impossibilidades estruturais e análises superficiais do ecoturismo. In: IV Seminário de Pesquisa em Turismo do Mercosul e III Seminário da Associação Nacional de Pesquisa e Pós Graduação em Turismo: Turismo: responsabilidade social e ambiental, 2006, Caxias do Sul RS. IV Seminário de Pesquisa em Turismo do Mercosul e III Seminário da Associação Nacional de Pesquisa e Pós Graduação em Turismo. Caxias do Sul: Universidade de Caxias do Sul e CNPq Conselho nacional de Desenvolvimento Científico e Tecnológico, 2006.

Neto, A. Z. Direito à paisagem. Revista Internacional de Direito e Cidadania, 2010. Disponível em 〈http://www.reid.org.br/arquivos/00000202-03-antonio zanollo.pdf> acesso em 03 de janeiro de 2016.

KERN, Maria Lúcia Bastos. História e arte: as invenções da paisagem. In: Anais do XXVI Simpósio Nacional de História. São Paulo, 2011.

SALGUEIRO, Teresa Barata. Paisagem e Geografia. In: Revista Portuguesa de Geografia. Lisboa, v. XXXVI, nº 72, 2001.

SAYÃO, THIAGO. Fotografia de paisagem no cartão-postal: atualização da imagem de Florianópolis na primeira metade do século vinte. In: Anais do XXVI Simpósio Nacional de História - ANPUH. São Paulo, julho de 2011.

VERRI, Paola. Ecoturismo: uma indústria sem chaminé?. São Paulo: FFLCH, 2008.

VITTE, Antonio Carlos. Da sensibilidade à representação da Paisagem: considerações sobre a estética da natureza como um recurso para a sensibilização ambiental. Disponível em http://ojs.c3sl.ufpr.br/ojs/index.php/raega/article/view/20601 acesso em 08 de janeiro de 2016.

XAVIER, Marina de Aquino Parreira. Búzios: Estética, poder e território. Dissertação de Mestrado. Universidade Federal do Rio de Janeiro. Rio de Janeiro, 2006. 